\section{BMJ Open} Ophthalmology

\title{
Temporal trends in ophthalmic surgical demand in a universal healthcare system: an Ontario population-based study of over two decades
}

Tina Felfeli (D) , ${ }^{1,2,3}$ Gener Austria, ${ }^{4}$ Reeza Menalo, ${ }^{4}$ Sherif R El-Defrawy, ${ }^{1,5}$ Diana Vasiliu, ${ }^{4}$ Claudia Zanchetta, ${ }^{4}$ Beate Sander ${ }^{2,3,6}$

\section{INTRODUCTION}

The global demand for eye health services is growing with increasing life expectancy and the ageing population. ${ }^{1}$ The estimated prevalence and relative contribution of avoidable causes of blindness and vision impairment globally is 9600 cases per 100000 people, with cataract and glaucoma as the leading global causes of blindness in those aged 50 years and older. ${ }^{1}$ Cataract surgery and other vision saving surgeries are among the most cost-effective healthcare interventions currently available. ${ }^{2}$ However, increasing case volume and backlogs in ophthalmic surgery will place unprecedented pressures on healthcare systems, particularly those with a limited ability to increase throughput. ${ }^{3}$ Data regarding demand and supply of surgery is required to inform surgical policies for optimal outcomes and equitable care. ${ }^{3}$

In many jurisdictions including the USA, there is a lack of population-based ophthalmic surgical data, and therefore, the unmet demand is unknown. The Canadian universal healthcare context is uniquely positioned to provide an overview of the demand for ophthalmic surgeries in a developed country. Herein, we report the trends in surgical volumes, wait times and characteristics of adult patients on the wait list in Ontario, the largest province in Canada's universal healthcare system.

\section{METHODS}

This is a population-based retrospective cohort study in Ontario, Canada, which permitted under CC BY-NC. No commercial re-use. See rights and permissions. Published by BMJ.

${ }^{1}$ Ophthalmology and Vision Sciences, University of Toronto, Toronto, Ontario, Canada

${ }^{2}$ The Institute of Health Policy, Management and Evaluation (IHPME), University of Toronto, Toronto, Ontario, Canada

${ }^{3}$ Toronto Health Economics and Technology Assessment (THETA) Collaborative, University Health Network, Toronto, Ontario, Canada

${ }^{4}$ Access to Care Program, Health System Performance and Support Portfolio, Ontario Health, Toronto, Ontario, Canada

${ }^{5}$ Kensington Eye Institute, Kensington Health, Toronto, Ontario, Canada

${ }^{6}$ Public Health Ontario, Toronto, Ontario, Canada

Table 1 Summary of average monthly ophthalmology surgical (all specialties combined) waitlist data over the study period

\begin{tabular}{llllll}
\hline Year & Cases added* & Cases cancelled* & $\begin{array}{l}\text { Volume of } \\
\text { completed } \\
\text { surgery* }\end{array}$ & $\begin{array}{l}\text { Wait list } \\
\text { queue* }^{*}\end{array}$ & $\begin{array}{l}\text { Wait time, } \\
\text { days-mean } \\
\text { (SD)* }\end{array}$ \\
\hline 2010 & $13843(1528)$ & $892(107)$ & $12633(1535)$ & $33715(1232)$ & $59(58)$ \\
\hline 2011 & $13951(1544)$ & $888(155)$ & $12947(1568)$ & $34999(1048)$ & $58(63)$ \\
\hline 2012 & $13988(1632)$ & $855(148)$ & $12791(1737)$ & $37671(1041)$ & $60(62)$ \\
\hline 2013 & $13476(1558)$ & $960(170)$ & $12462(1736)$ & $41380(822)$ & $67(67)$ \\
\hline 2014 & $13609(1330)$ & $863(153)$ & $12283(1601)$ & $42471(2144)$ & $69(70)$ \\
\hline 2015 & $13643(1288)$ & $830(115)$ & $12170(1491)$ & $49821(2535)$ & $77(73)$ \\
\hline 2016 & $13906(1428)$ & $922(152)$ & $12746(1580)$ & $54792(765)$ & $84(83)$ \\
\hline 2017 & $13987(1458)$ & $914(174)$ & $12952(1544)$ & $57985(1307)$ & $91(94)$ \\
2018 & $14427(1303)$ & $822(195)$ & $13289(1441)$ & $59075(1269)$ & $90(94)$ \\
\hline 2019 & $14411(1488)$ & $936(274)$ & $13509(1431)$ & $58708(1073)$ & $89(96)$ \\
2020 & $14108(1392) \ddagger$ & $742(80) \ddagger$ & $13998(893) \ddagger$ & $58628(225) \ddagger$ & $91(95)$ \\
\hline
\end{tabular}

*Monthly average between January and December.

†As of first day of Month.

¥Up to but not including March 2020. 


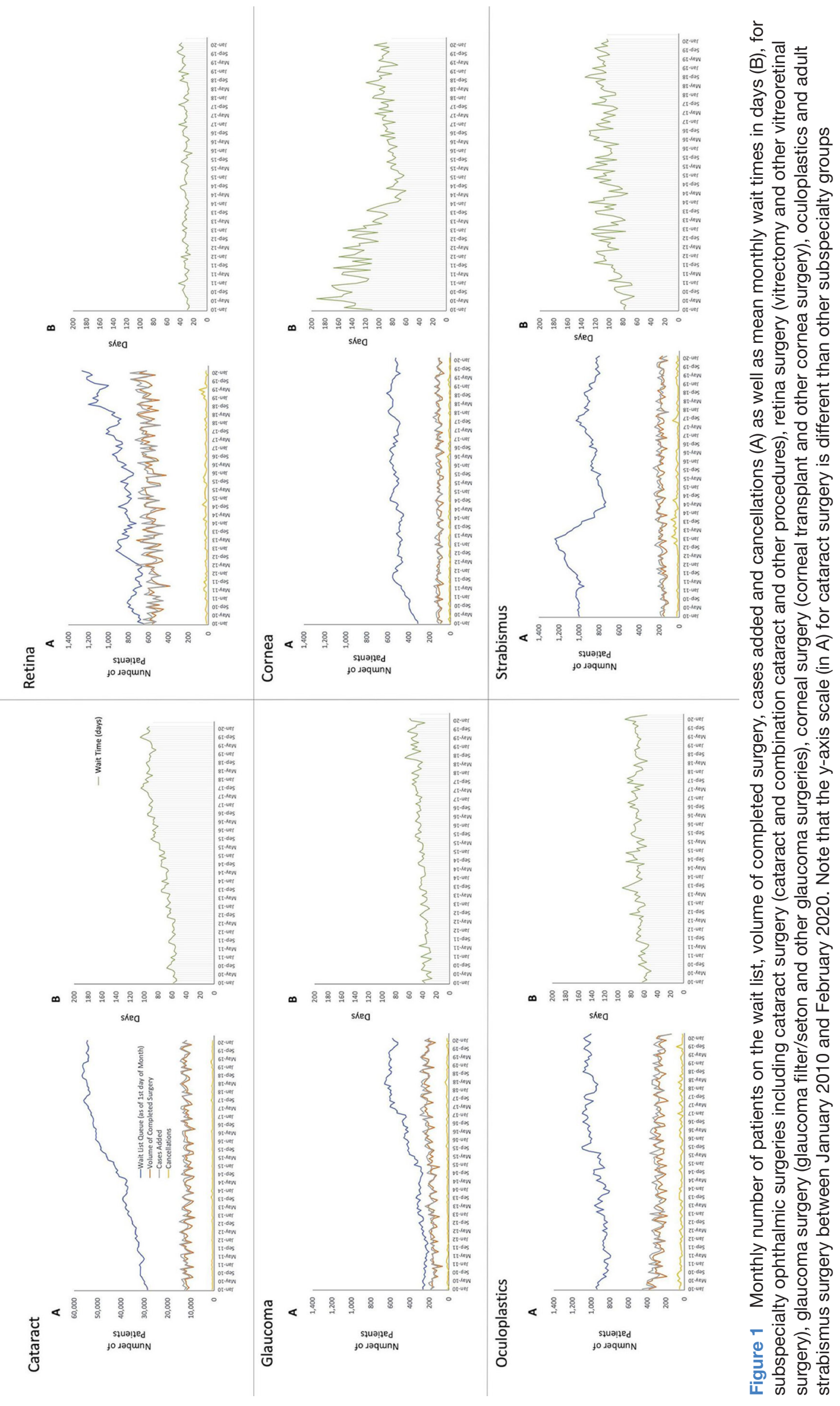

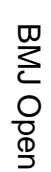

음

$\stackrel{\vec{F}}{\stackrel{9}{+}}$

흥

$\stackrel{\nabla}{\square}$

क 
followed the Strengthening the Reporting of Observational Studies in Epidemiology reporting guideline.

Data for the period of January 2010 to February 2020 were obtained from the provincial Wait Times Information System (WTIS) from Ontario Health, which comprehensively captures any surgical wait list data on the Ontario adult population of 14.8 million. Ontario Health is authorised to collect population-level data for the purpose of monitoring allocation of resources and delivery of services. The WTIS captures wait time data in near real time ${ }^{4}$ on wait list queues for non-emergency ophthalmic surgical procedures (subspecialty surgeries including vitreoretinal, glaucoma, cornea, cataract, oculoplastics and adult strabismus surgery), ${ }^{5}$ the number of new cases added to the wait list, the number of completed surgeries performed, as well as patient demographics (age and sex). Additionally, the WTIS captures the wait time in days (mean and SD) for patients on the wait list.

All results are reported descriptively with means, medians and margins of error (SD and IQR). For determining trends over time, per cent change calculations were used. Statistical analysis was performed using SAS Enterprise Guide V.7.15 (SAS Institute).

\section{RESULTS}

Over the study period of 2010-2020, a total of 1699087 adult cases were added to the list for non-emergency ophthalmic surgery. This is equivalent to approximately 13927 (SD 1429) cases added to the ophthalmic surgical weight list per month (or 94 cases/month/100 000 people). Among patients who underwent surgery, females represented $56 \%$ of all cases. The median age of all patients was 73 (IQR: 65-79) years in 2010 and 72 (IQR: 66-78) years in 2021. The youngest patient group on the waitlist was awaiting surgery for adult strabismus (median age: 45; IQR: 30-62 in 2020).

The number of patients awaiting ophthalmic surgery for all subspecialties between 2010 to 2020 grew by $74 \%$ (33 715 (SD 1,232) vs 58628 (SD 225)). The mean number of cases added per month between 2010 and 2020 increased by approximately 265 cases from 13843 (SD 1528) to 14108 (SD 1392). Between 2010 and 2020, a total of 1561376 ophthalmic surgeries were completed, with an average of 12798 (SD 1,558) cases performed per month over the study period. The mean monthly number of patients added to the wait list for surgery exceeded the number of surgeries being completed each month by 1129 (SD 660) additional cases. Accordingly, the wait time for patients on the wait list increased from 59 (SD 58) days to 91 (SD 95) days over the study period (table 1). With the increasing volume of completed surgery in 2018 and onwards, the wait list queue was noted to stabilise in more recent years.

With regard to each of the subspecialties, in 2020, cataract had the highest monthly number of patients on the waitlist (54427 (SD 234) patients), followed by vitreoretinal surgery (1277 (SD 52), figure 1A). Among all subspecialties, the mean wait time in 2020 was highest for adult strabismus surgery at 102 (SD 112) days. The largest increase in wait time between 2010 and 2020 was noted for cataract surgery at $48.7 \%$ (figure 1B). During the study period, there were on average 886 (SD 169) cancellations per month for patients awaiting ophthalmic surgery.

\section{DISCUSSION}

The findings from this population-based study suggest that there is an unmet demand for ophthalmic surgeries in the Ontario, Canada population over the past decade. The growing waitlist may be in part attributed to the gap between cases added and surgeries performed each month since 2010, which has started to stabilise in more recent years with the increasing number of completed surgeries. We have previously reported that there are approximately 478 ophthalmologists in Ontario as of $2018 .{ }^{67}$ This suggests that there is one ophthalmologist for every 123 patients on the wait list. There was also a relatively high number of cancellations in the publicly funded ophthalmic surgery wait list, which suggests that the unmet demand for eye care may be even higher than reported here. Given the similarity in demographic characteristics of Canada and the USA and other developed nations, analogous increases in demand are anticipated in other jurisdictions. Implementation of strategies for addressing the unmet demand for subspecialty surgeries may help the burden of avoidable blindness.

Contributors Conception and design: TF. Acquisition of data: TF, GA, RM, DV and CZ. Data analysis: TF and GA. Interpretation of data: TF, SRE-D nd BS. First draft of the article: TF. Critical revision: TF, GA, RM, SRE-D, DV, CZ and BS.

Funding This research was supported by COVID-19 Rapid Research Funding (C-291-2431272-SANDER) through the Ontario Ministry of Health, Ontario Together grant.

Disclaimer The funding organisations had no role in the design or conduct of this research.

Competing interests None declared.

Patient consent for publication Not applicable.

Ethics approval Ethics approval for the conduction of this study was obtained from University of Toronto Research Ethics Board (RIS protocol number: 41582). This is a population-based study involving a database of anonymous data. The University of Toronto Research Ethics Board waived the need for individual patient consent for this study.

Provenance and peer review Not commissioned; externally peer reviewed.

Open access This is an open access article distributed in accordance with the Creative Commons Attribution Non Commercial (CC BY-NC 4.0) license, which permits others to distribute, remix, adapt, build upon this work non-commercially, and license their derivative works on different terms, provided the original work is properly cited, appropriate credit is given, any changes made indicated, and the use is non-commercial. See: http://creativecommons.org/licenses/by-nc/4.0/.

ORCID iD

Tina Felfeli http://orcid.org/0000-0002-0927-3086

\section{REFERENCES}

1 GBD 2019 Blindness and Vision Impairment Collaborators, Vision Loss Expert Group of the Global Burden of Disease Study. Causes of blindness and vision impairment in 2020 and trends over 30 years, and prevalence of avoidable blindness in relation to vision 2020 : 
the right to sight: an analysis for the global burden of disease study. Lancet Glob Health 2021;9:e144-60.

2 Lansingh VC, Carter MJ, Martens M. Global cost-effectiveness of cataract surgery. Ophthalmology 2007:114:1670-8.

3 Felfeli T, Ximenes R, Naimark DMJ, et al. The ophthalmic surgical backlog associated with the COVID-19 pandemic: a population-based and microsimulation modelling study. CMAJ Open 2021;9:E1063-72.

4 Statistics Canada. Population estimates, quarterly. Ottawa (ON), Published 2020. Available: https://www150.statcan.gc.ca/t1/tbl1/ en/ tv.action?pid=1710000901 [Accessed 29 Dec 2020].
5 Ontario Health. Ontario wait times strategy. Available: https://www. ontariohealth.ca [Accessed 27 Dec 2020].

6 Felfeli T, Canizares M, Jin Y-P, et al. Pay Gap among Female and Male Ophthalmologists Compared with Other Specialties. Ophthalmology 2022;129:111-3.

7 Buys YM, Canizares M, Felfeli T, et al. Influence of Age, Sex, and Generation on Physician Payments and Clinical Activity in Ontario, Canada: An Age-Period-Cohort Analysis. Am J Ophthalmol 2019;197:23-35. 